\title{
DETERMINATION OF METHYL MERCURY IN A PILOT-SCALE ACTIVATED SLUDGE WASTEWATER TREATMENT PLANT
}

\author{
G.D. PAVLOGEORGATOS ${ }^{1}$ \\ N.S. THOMAIDIS ${ }^{2}$ \\ A.D. NIKOLAOU ${ }^{3,4^{*}}$ \\ T.D. LEKKAS ${ }^{3}$
}

\author{
${ }^{1}$ Department of Cultural Technology and Communication \\ University of the Aegean \\ Sapfous and Arionos str. 81-100 Mytilene, Lesvos, Greece \\ ${ }^{2}$ Laboratory of Analytical Chemistry \\ Department of Chemistry \\ University of Athens, Panepistimiopolis \\ 15771 Athens, Greece \\ ${ }^{3}$ Water and Air Quality Laboratory \\ Department of Environmental Studies \\ University of the Aegean \\ University Hill, 81100 Mytilene, Greece \\ ${ }^{4}$ Department of Marine Sciences \\ University of the Aegean \\ University Hill, 81100 Mytilene, Greece
}

Selected from papers presented in $9^{\text {th }}$ International Conference on Environmental

Science and Technology (9CEST2005)

*to whom all correspondence should be addressed e-mail: nnikol@aegean.gr

1-3 September 2005, Rhodes island, Greece

\section{ABSTRACT}

The methylation of mercury has been investigated and documented mainly in sediments, fish and microorganisms, while limited number of relevant studies is available for wastewater. The procedure of mercury methylation can occur via biological pathway (by microorganisms) and via chemical or photochemical reactions.

Methylation of mercury occurs mainly under anaerobic conditions, but some studies have shown its existence also under aerobic conditions. The resulting concentration of methyl mercury, which is a highly toxic compound, depends on the specific rates of methylation/demethylation of mercury. The factors affecting these procedures are the availability of inorganic mercury, $\mathrm{pH}$, organic matter concentration, microbial activity, redox potential and temperature. Bacteria which can methylate mercury are often present in wastewater, and, therefore, the formation of methyl mercury during wastewater treatment is possible.

The objective of the present investigation was the determination of methyl mercury in a pilotscale activated sludge wastewater treatment plant supplied with synthetic wastewater enriched with mercury. For this purpose, a Liquid-Liquid Extraction / Simultaneous Derivatization - GC/MS method was developed and applied for the analysis of samples from the aeration tank, from the treatment plant effluent and from the sludge.

Methyl mercury was not detected in the samples (detection limit $0.07 \mu \mathrm{g} \mathrm{I}^{-1}$ ), leading to the conclusion that mercury is not methylated under the particular experimental conditions of the pilot-scale water treatment plant.

KEYWORDS: methyl mercury, wastewater, activated sludge, Gas chromatography - Mass spectrometry (GC/MS), Liquid-Liquid Extraction, derivatization 


\section{INTRODUCTION}

The process of methylation of mercury has been investigated mainly in sediment, in fish and in microorganisms, and occurs at a large extent in sediments of lakes, rivers and oceans [1]. The process of methylation of mercury in natural ecosystems may follow the following pathways [2-3]:

- Biological activity by various species of microorganisms, mainly bacteria

- Chemical reactions through humic substances

- Photochemical processes.

The concentration of methyl mercury in a system depends on the relative rates of methylation and de-methylation of $\mathrm{Hg}$. The particular processes are affected by the availability of inorganic mercury, $\mathrm{pH}$, the amount of organic matter, the microbial activity [4], the redox potential and the temperature [4-5]. The methylation is enhanced by temperature increase. At neutral $\mathrm{pH}$, the monomethylmercury is the dominant species [6]. According to Bisogni [4], the rate of methylation of $\mathrm{Hg}$ is described by the equation:

$N S M R=V^{*}\left(\mathrm{Hg}^{2+}\right) n$

where:

NSMR (Net Specific Methylation Rate): the actual methylation rate $\left(\mu \mathrm{g}\left(\mathrm{CH}_{3}\right)_{2} \mathrm{Hg}\right.$ or $\mathrm{CH}_{3} \mathrm{Hg}^{+}$ per gr of volatile suspended solids)

$\mathrm{Y}$ : coefficient determined from the rate of growth of microorganisms

$\left(\mathrm{Hg}^{2+}\right)$ : concentration of free $\mathrm{Hg}$ ions

$\mathrm{n}$ : pseudo-rate of the reaction

Methylation of mercury usually occurs in anaerobic conditions, but it has also been reported to occur also in aerobic conditions, with lower yields of methyl mercury $[4,7]$. Microorganisms play an important role during the mercury methylation procedure. Increased growth and metabolism of microorganisms enhances methylation. Several species of bacteria that are capable of methylating mercury in aquatic and in terrestrial ecosystems are frequently detected also in wastewater, in considerable concentrations, e.g. pseudomonas spp. [4].

An activated sludge wastewater treatment plant could be considered as a simplified natural system where $\mathrm{pH}$ and redox potential remain unchanged. Therefore, while the temperature increase and the high concentration of suspended solids accelerate the methylation of mercury, the aerobic conditions support the growth of bacteria which demethylate the methyl mercury to inorganic mercury.

Research regarding the possible methylation of mercury during activated sludge wastewater treatment, especially for full-scale plants, is limited [7-9]. Goldstone [7] investigated methyl mercury in a full scale wastewater treatment plant in Norwich, and found that a percentage $<0,5 \%$ of the input $\mathrm{Hg}$ occurred as methyl mercury. In particular, in the mixed liquor (in 1986)

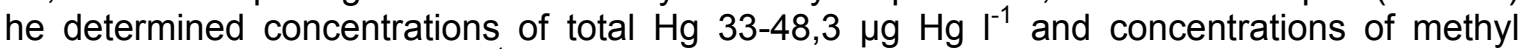
mercury $0,07-0,24 \mu \mathrm{g} \mathrm{MeHg}^{-1}$ respectively. Research continued in the same treatment plant the next two years showed not detectable concentrations of methyl mercury (detection limit 10 $\mathrm{ng} \mathrm{I}^{-1}$ ). Bisoqni et al [4] found that the percentage of input mercury chloride that was converted to methyl-mercury ranged from 0,1 to $15 \%$. In contrast, Wu et al [10] reported only traces of methyl mercury in the treatment plant effluent, and correlated the existence of methyl mercury to the existence of solids. The average concentration of methyl mercury determined by Gilmour [11], in a full- scale wastewater treatment plant was $0.104 \mathrm{~g} \mathrm{~d}^{-1}$ in the influent (for $19.3 \mathrm{~g} \mathrm{~d}^{-1}$ inorganic mercury), $0.269 \mathrm{~g} \mathrm{~d}^{-1}$ in the effluent (for $12.8 \mathrm{~g} \mathrm{~d}^{-1}$ inorganic mercury) and $0.125 \mathrm{~g} \mathrm{~d}^{-1}$ in sludge (for $144 \mathrm{~g} / \mathrm{d}$ inorganic mercury). According to Gilmour, although the influent contained methyl mercury, $\mathrm{Hg}$ was methylated during the wastewater treatment at percentage $<5 \%$ of the total incoming $\mathrm{Hg}$. Also, demethylation of methyl mercury was observed during aeration of wastewater.

During collection and transport of wastewater in a treatment plant, bivalent $\mathrm{Hg}(\mathrm{II})$ is exposed to reductive conditions (due to poor oxygenation and existence of some species of bacteria), and therefore converted to elementary $\mathrm{Hg}^{(0)}$. Elementary mercury may be released into the atmosphere especially during aeration [6]. In the primary sedimentation tank, the mercury is highly associated to the suspended solids and removed along with the sludge. Goldstone [7] 
determined that via this pathway, $30-60 \%$ of the incoming $\mathrm{Hg}$ in the treatment plant may be removed. In the aeration tank, a large number of microorganisms (bacteria, protozoa etc) transform $\mathrm{Hg}$ to organic forms, with dominant methyl mercury, and vice versa. The concentrations of the chemical species of mercury depends on the rates of methylationdemethylation, which in turn depend on microorganisms, temperature, redox potential, $\mathrm{pH}$ and suspended solids, as mentioned above. Therefore, although the effectiveness of mercury removal in the wastewater treatment plants is high, methyl mercury could be formed, which consists an environmental risk.

The objective of the present investigation was the determination of methyl mercury in a pilotscale activated sludge wastewater treatment plant, which was supplied with synthetic wastewater enriched with mercury. The determination of organic mercury species in environmental samples is generally performed by gas chromatography (GC) techniques, which include extraction, derivatization, concentration, separation and detection. The most reliable detection technique is Mass Spectrometry (MS), which provides detailed data regarding compound identification. During this work, a Liquid-Liquid Extraction / Simultaneous Derivatization - GC/MS method was developed and applied for the analysis of wastewater samples from the aeration tank, from the treatment plant effluent and from the sludge.

\section{MATERIALS AND METHODS}

\subsection{Experimental setup and sampling}

A pilot scale activated sludge wastewater treatment plant was constructed as described in detail by Pavlogeorgatos [12-16] (Figure 1). The operational parameters of the pilot plant are presented in Table 1. The plant was supplied with synthetic wastewater, which contained $0.325 \mathrm{~g}$ glucose per liter of tap water. The nutrients were added with the introduction of $0.2 \mathrm{~g}$ thiophosphoric ammonia per liter of water. The synthetic wastewater that supplied the treatment plant was enriched with mercury at concentration levels 10,100 and $500 \mathrm{\mu g} \mathrm{I}^{-1}$. The increase of mercury concentration was performed at 3-day intervals. Sampling (in duplicate) was performed for each $\mathrm{Hg}$ concentration level, from the aeration tank, the treatment plant effluent and the sludge. Measurements of temperature, $\mathrm{pH}$ and dissolved oxygen were performed daily. Samples were also analyzed for COD for each investigated input concentration of $\mathrm{Hg}$, as well as twice before the enrichment with mercury. Suspended solids were also determined twice before the enrichment with $\mathrm{Hg}$ and once for input concentration of $\mathrm{Hg} 500 \mu \mathrm{I} \mathrm{I}^{-1}[13]$.

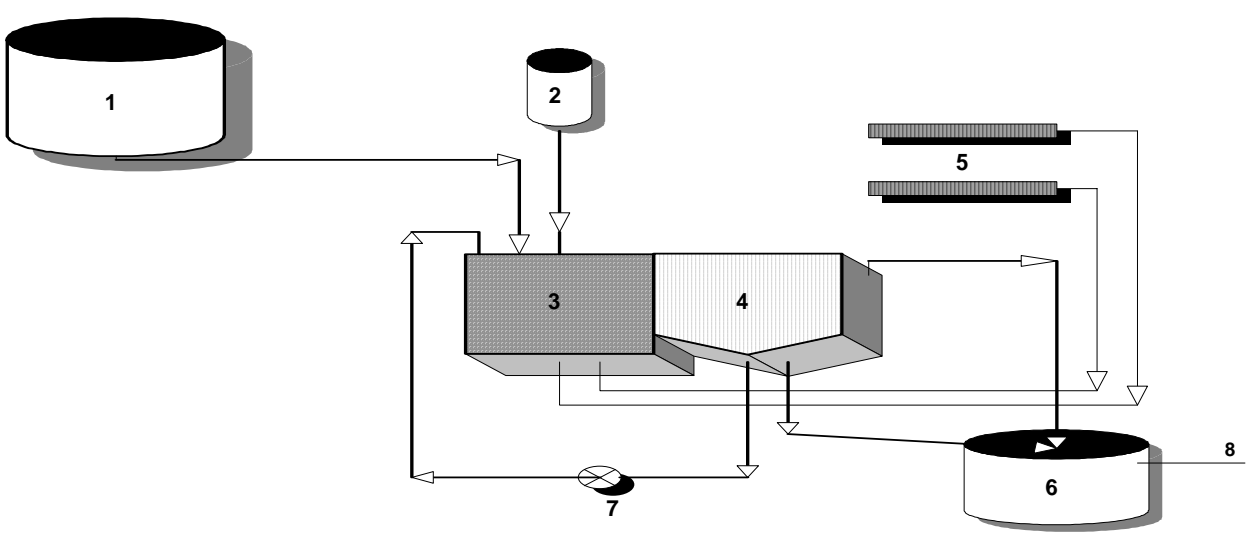

Figure 1. Scheme of the activated sludge pilot plant [12]

1. Mixture tank of glucose and macro-nutrients 2 . Mercury- containing feed tank 3 . Aeration tank 4. Precipitation tank 5. Air compressors 6 . Treated wastes tank 7. Return sludge pump

8. Outlet of the plant 
Table 1. Operational parameters of the activated sludge pilot plant [12-13]

\begin{tabular}{cccc}
\hline Parameter & Value & Parameter & Value \\
\hline$V_{\mathrm{AT}^{*}}$ & $80 \mathrm{I}$ & $\mathrm{S}$ & $20 \mathrm{mg} \mathrm{l}^{-1}$ \\
\hline $\mathrm{V}_{\mathrm{PT}^{\star *}}$ & $40 \mathrm{t}$ & Eo & $93 \%$ \\
\hline$\Theta$ & $5 \mathrm{~h}$ & Concentration of fertilizer & $0,2 \mathrm{~g} \mathrm{I}^{-1}$ \\
\hline $\mathrm{Oc}$ & $7 \mathrm{~d}$ & $\mathrm{Q}$ & $340 \mathrm{I}^{-1}$ \\
\hline $\mathrm{X}$ & $3,000 \mathrm{mg} \mathrm{I}^{-1}$ & $\mathrm{Q} / \mathrm{Qr}$ & 1 \\
\hline So & $300 \mathrm{mg} \mathrm{l}^{-1}$ & $\mathrm{~A}_{\mathrm{AT^{* }}}$ & $257 \mathrm{~cm}^{2}$ \\
\hline
\end{tabular}

$\mathrm{AT}^{*}$ : Aeration Tank

$\mathrm{PT}^{* *}$ : Precipitation Tank

\subsection{Reagents-Standard solutions}

The ultrapure water used was type 1, from Milli RO5/MilliQ 185 columns (Millipore). The following high-purity reagents were also used: $\mathrm{NaBet}_{4}$ (Merck) solution $1 \%, \mathrm{NaCl}$ (Merck), sodium acetate (Merck), acetic acid (Merck) and hexane (BDH). A stock solution $10 \mathrm{mg} \mathrm{MeHg}$ $\mathrm{I}^{-1}$ was prepared in hexane from a certified $\mathrm{MeHg}$ standard (solid, $\mathrm{CH}_{3} \mathrm{HgCl}$ ), Aldrich Chem Co, by dilution of the appropriate amount. This stock solution was used for the preparation of standard solutions of known concentrations for the GC-MS system calibration. A stock solution $1000 \mathrm{mg} \mathrm{I}^{-1} \mathrm{Hg}\left(\mathrm{HgNO}_{3}\right)$ (Merck) was also used for the preparation of standard calibration solutions for the determination of $\mathrm{Hg}$.

\subsection{Sample preparation}

Following shaking of the plastic bottle containing the standard or sample, to $200 \mathrm{ml}$ of sample $30 \mathrm{gr} \mathrm{NaCl}$ plus $2.72 \mathrm{gr} \mathrm{CH} \mathrm{CHOONa}_{3} \mathrm{Cre}$ added. Some drops of $\mathrm{CH}_{3} \mathrm{COOH}$ or $\mathrm{NaOH}$ were also added for $\mathrm{pH}$ adjustment to 4.5. The solution was placed in a magnetic stirrer for $5 \mathrm{~min}$ to obtain proper dilution and then it was transferred into a separatory funnel, where $20 \mathrm{ml}$ hexane and $2 \mathrm{ml} \mathrm{NaBEt}$. 1\% were added. Liquid-liquid extraction with simultaneous derivatization (ethylation) was performed for 20 min and then the solution was left undisturbed for approximately $40 \mathrm{~min}$, for phase separation. Finally, the solution was centrifuged for 10 min at 2,000 rpm and the supernatant was concentrated $(x 10)$ under a gentle stream of nitrogen (purity $99.999 \%$ ). $1 \mu \mathrm{l}$ of the final extract was injected into the GC-MS.

\subsection{Equipment-Analytical conditions}

The determination of MeEthHg and DiEthHg was performed by use of a HP 5890 Series II gas chromatograph (GC) with a Hewlett Packard 5971 Mass Selective Detector (MSD). The column used was fused silica capillary DB-624 $30 \mathrm{~m} \times 0.32 \mathrm{~mm}$ i.d. $\times 1.8 \mu \mathrm{m}$, the injection technique was split/splitless and the carrier gas was helium (purity 99.999\%). The analytical conditions are presented in Table 2 and a GC-MS chromatogram in Fig 2.

\subsection{Recovery tests and detection limit of the method}

Recovery tests for MeHg were conducted in biomass substrate from the activated sludge pilot plant described above in samples from the aeration tank of the plant and from the sludge, after spiking with $2 \mathrm{mg} \mathrm{MeHg} \mathrm{I}^{-1}$ (six replicates). The recovery of $\mathrm{MeHg}$ was $98 \%$ (RSD 2,5\%) for the samples from the aeration tank and $90 \%$ (RSD 3,8\%) for the sludge samples. The recovery of DiEthHg was $85 \%$ (RSD 6\%). The detection limit of the method described, estimated based on signal-to-noise ratio $2 / 1(\mathrm{~S} / \mathrm{N}=2 / 1)$, was $0.07 \mu \mathrm{g} \mathrm{MeHg} \mathrm{I^{-1 }}$. For mercury, the detection limit was $2 \mu \mathrm{g} \mathrm{Hg} \mathrm{l}^{-1}$.

\section{RESULTS AND DISCUSSION}

The analytical technique utilized during the present work (GC-MS) is one of the most reliable techniques for the determination of methyl mercury, and the recovery tests have shown very satisfactory results. Moreover, the high temperature during the pilot-plant experiment as well as the high concentration of suspended solids are factors which should enhance the methylation of mercury $[5,7,9]$. Taking into account these facts, the formation of methyl mercury would be expected. 
Table 2. Analytical conditions of GC-MS for the determination of MeEthHg and DiEthHg

\begin{tabular}{lc}
\hline \multicolumn{2}{c}{ GC analytical conditions } \\
\hline Carrier gas flow: & $1.25 \mathrm{ml} \mathrm{min}^{-1}$ \\
\hline Split ratio: & $1: 25$ \\
\hline Oven temperature program: & $\begin{array}{l}\text { Initial temperature } 60^{\circ} \mathrm{C}(2 \mathrm{~min}) \\
\text { Rate of increase } 20^{\circ} \mathrm{C} \mathrm{min}-1\end{array}$ \\
& Final temperature $200^{\circ} \mathrm{C}$ \\
\hline Injector temperature: & $200^{\circ} \mathrm{C}$ \\
\hline \multicolumn{2}{l}{ MS analytical conditions } \\
\hline Solvent delay: & $5 \mathrm{~min}$ \\
\hline MS transfer line temperature: & $280^{\circ} \mathrm{C}$ \\
\hline EMV: & 2200 \\
\hline SIM Mode & Ions $217,202,244,252,231$ \\
\hline
\end{tabular}

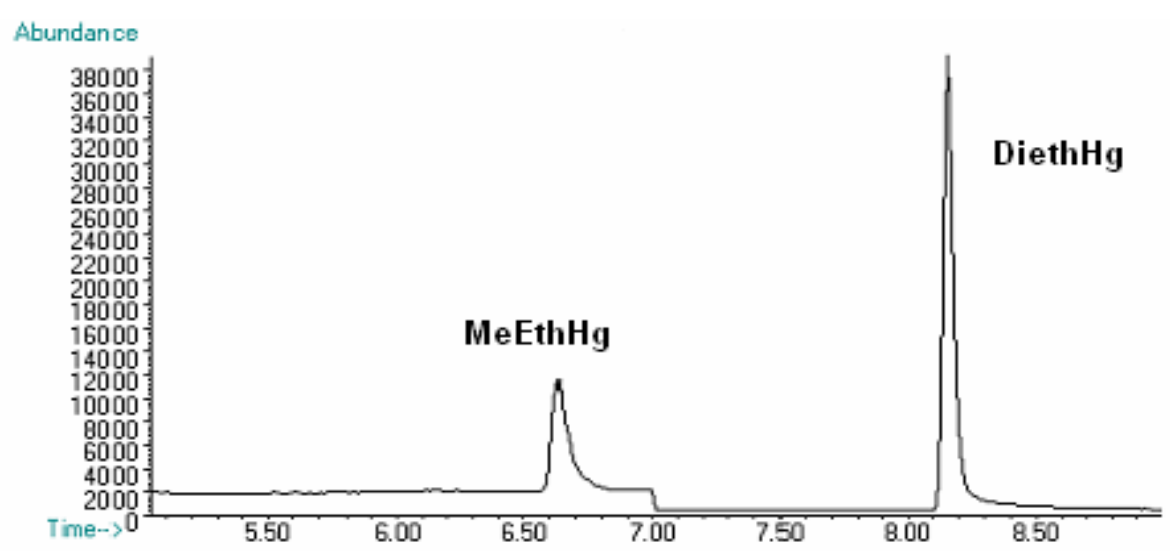

Figure 2. GC-MS Chromatogram of a standard solution Me-EthHg and DiethHg $2.5 \mathrm{mg} \mathrm{I}^{-1}$

However, in all samples analyzed, the concentration of methyl mercury was not detectable (detection limit $0.07 \mu \mathrm{g} \mathrm{MeHg} \mathrm{I}^{-1}, \mathrm{~S} / \mathrm{N}=2 / 1$ ). The sample where the highest concentration of total mercury was determined was the sludge sample after input of $500 \mathrm{\mu g} \mathrm{Hg} \mathrm{l}^{-1}$ in the treatment plant. In the particular sample, the total mercury concentration was $17,8 \mathrm{mg} \mathrm{Hg} \mathrm{I}^{-1}$ (Figure 3). In average, the $82,8 \pm 7,4 \%$ of the input dissolved $\mathrm{Hg}$ into the plant was adsorbed to the particular matter of the aeration tank, a fact explaining the high removal capacity of the plant for $\mathrm{Hg}$. However, this percentage decreases somewhat in the effluent (the corresponding percentage adsorbed to the particulate matter of the effluent was $76,22 \pm$ $14,5 \%)$.

During this investigation it was confirmed that the reduction of the incoming $\mathrm{Hg}$ and its subsequent volatilization is one of the major mechanisms of its removal. As soon as the microorganisms of the aeration tank become acclimatized to the presence of $\mathrm{Hg}$, this mechanism becomes the second removal mechanism, the first being the adsorption of $\mathrm{Hg}$ onto the flocs.

The enrichment of the pilot plant with $\mathrm{Hg}$ resulted in significant reduction of the removal capacity for organic matter. For concentrations of $\mathrm{Hg}$ lower than $100 \mu \mathrm{g} \mathrm{I}^{-1}$, the average decrease of the organic matter removal capacity was $10 \%$, while for $\mathrm{Hg}$ concentrations higher than $100 \mathrm{mg} \mathrm{I}^{-1}$, it was $15 \%$.

In the relevant literature, contradictory results have been published regarding the methylation or not of the mercury in wastewater treatment plants. In some cases methyl mercury was not detected, whereas in other studies $0.5 \%-15 \%$ of the total mercury has been reported to be methylated.

A possible reason for the absence of methyl mercury from the analyzed wastewater samples is that the conditions were aerobic, a fact that does not favor the methylation procedure. In 
addition, since the ratio methylation/demethylation is directly affected by the numbers and species of microorganisms $[1,7]$, it can be assumed that under the particular conditions the demethylation procedure was predominant.

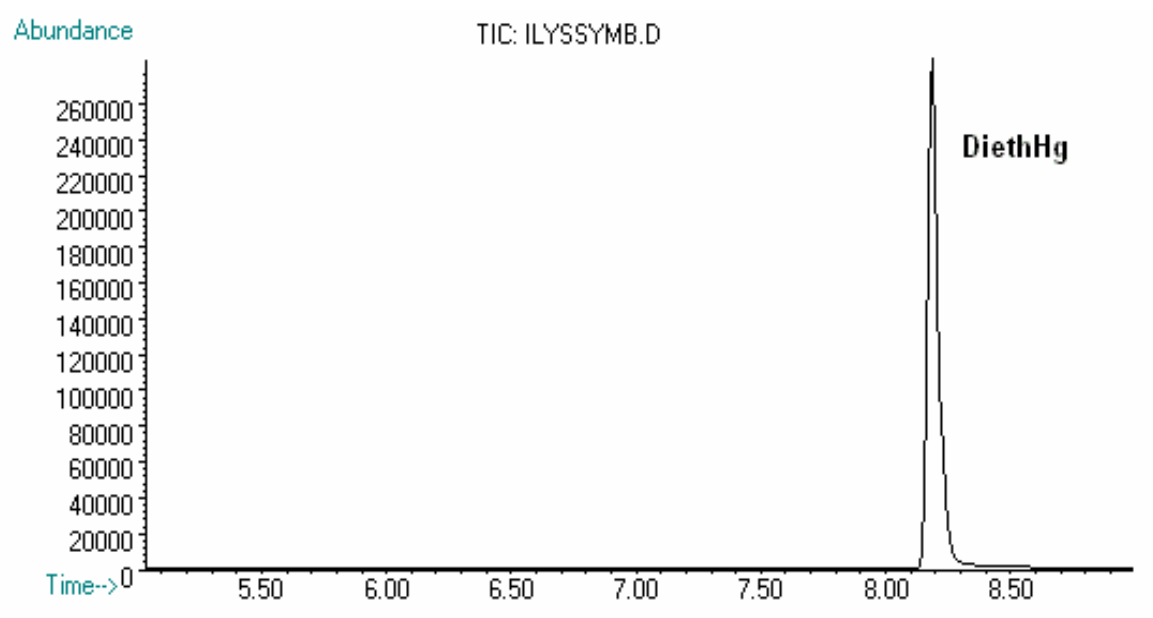

Figure 3. GC-MS chromatogram in the sludge sample with the highest $\mathrm{Hg}$ concentration

The determination of methyl mercury, especially in wastewater samples, shows analytical difficulties, mainly poor sensitivity of the methods. Up to now, research on analytical methods optimization is in progress. The existing analytical methods are time consuming, expensive and need high scientific expertise. Moreover, according to the existing regulations in Europe and in the USA, the determination of methyl mercury in wastewater treatment plants is not obligatory. Therefore, the references regarding the formation of methyl mercury during wastewater treatment are still very scarce, especially for full-scale plants [8-9, 17-20]. An issue of concern, given the elevated concentrations of total $\mathrm{Hg}$ in municipal wastewater, is the environmental and health risk posed by the possible existence of methyl mercury at concentrations lower than the detection limits obtained with the currently available analytical techniques.

\section{CONCLUSIONS}

A simultaneous extraction-derivatization method was developed for the determination of $\mathrm{MeHg}$ in wastewater, and applied for the examination of $\mathrm{Hg}$ methylation in a pilot-plant activated sludge wastewater treatment plant supplied with synthetic wastewater enriched with $\mathrm{Hg}$. Under these particular conditions, methylation of $\mathrm{Hg}$ did not occur, although the high temperature during the pilot-plant experiment and the high concentration of suspended solids are factors which should enhance the methylation of mercury. The fact that the conditions were aerobic, as well as the speciation of microorganisms in the particular case could be the reason that $\mathrm{Hg}$ was not methylated during the present experiment.

During this investigation it was also confirmed that the reduction of the incoming $\mathrm{Hg}$ and its subsequent volatilization is one of the major mechanisms of its removal, while after the acclimatization of the microorganisms of the aeration tank, this mechanism becomes the second removal mechanism, the first being the adsorption of $\mathrm{Hg}$ onto the flocs. Another observation was that the enrichment of the pilot plant with $\mathrm{Hg}$ resulted in significant reduction of the removal capacity for organic matter.

\section{REFERENCES}

1. Jansen S. and Jernelov A. (1969), Biological methylation of mercury in aquatic organisms, Nature (London U.K.), 223, 753-754.

2. Ansari M.H., Deshkar A.M., Kelkar P.S., Dharmadhikari D.M., Hasan M.Z. and Paramasivam R. (1999), Mercury removal from Wastewater by Streamed Hoof Powder, Wat. Sci. Tech., 40, $7,109-116$. 
3. Pavlogeorgatos G. and Kikilias V. (2003), The importance of mercury determination and speciation to the health of the general population, Global Nest: the Int. J., 4 (2-3), 107-125.

4. Bisogni J.J. and Lawrence A.W. (1975), 'Kinetics of mercury methylation in aerobic and anaerobic aquatic environments', J.W.P.C.F., 47, 1, 135-152.

5. Xun L., Campbell N. and Rudd J.W. (1987), Measurements of specific rates of net methyl mercury production in the water column and surface sediments of acidified and circumneutral lakes, Can. J. Fish. Aquat. Sci., 44, 750-757.

6. US EPA, (1997). Mercury study, report to congress, in Volume III: Fate and Transport of Mercury in the Environment, Office of Air Quality Planning \& Standards and Office of Research and Development.

7. Goldstone M.E., Atkinson C., Kirk P.W.W. and Lester J.N. (1990), The behaviour of heavy metals during wastewater treatment III. Mercury and arsenic, Sci. Total Environ., 95, 271-294.

8. Huber K. (1997), The Wisconsin Mercury SourceBook, US EPA Pollution Prevention Incentives for States Grant \#NP985072-01-1, Wisconsin Department of Natural Resources Bureau of Watershed Management (WT/2), P.O. Box 7921, Madison, Wisconsin 53707-7921 (608) 267-7694.

9. Mugan T. (1993), Quantification of Total mercury Discharges from Municipal Wastewater Treatment Plants to the Wisconsin Surface Waters, WDNR, May 1993.

10. Wu J.S. and Hilger H. (1985). Am. Inst. Chem. Eng., 81, 109.

11. Gilmour C. and Bloom N. (1995), A case study of mercury and methylmercury dynamics in a Hg-contaminated municipal wastewater treatment plant, Water, Air, Soil Pollut. 80, 799-803.

12. Pavlogeorgatos G. (2003), Effect of mercury contaminated wastewater on activated sludge suspended solids size distribution, Toxicol. and Environ. Chemistry 85(4-6), 159-167.

13. Pavlogeorgatos G. (2001), The fate of mercury in an activated sludge pilot plant, PhD thesis, Department of Environmental Studies, University of the Aegean, Greece (in Greek).

14. Pavlogeorgatos G., Lekkas Th., Georgiou V., Spachos G., Stefanoulis C. and Tridimas P. (1999a), Examination of mercury's effects during the process of the activated sludge Toxicol. and Environ. Chemistry, 69, 171.

15. Pavlogeorgatos G., Lekkas T. and Savopoulou S. (1999b), Determination of dissolved and particulate mercury at the activated sludge process, 6th International Conference on Environmental Science and Technology, Samos, 30/8-2/9/99, Vol. C., pp.461-466 (in Greek).

16. Pavlogeorgatos G., Lekkas T., Georgiou B., Spachos G., Stefanoulis C., Tridimas P. and Savopoulou S. (1998), Estimation of mercury's removal ability in an activated sludge pilot plant and examination of mercury's effects during the process of the activated sludge, Proc. Int. Conference Protection and Restoration of the Environment IV, 1-4/7/98, Halkidiki, Greece, vol. 2, pp.593-600.

17. US EPA (1997a) Mercury study, report to congress, in Volume II: An Inventory of Anthropogenic Mercury Emissions in the United States, Office of Air Quality Planning \& Standards and Office of Research and Development.

18. US EPA, (1997b) Mercury study, report to congress, in Volume III: Fate and Transport of Mercury in the Environment, Office of Air Quality Planning \& Standards and Office of Research and Development.

19. US EPA, (1997c), Mercury study, report to congress, Volume IV: An Assessment of Exposure to Mercury in the United States, Office of Air Quality Planning \& Standards and Office of Research and Development.

20. US EPA, (1997d), Mercury study, report to congress, in Volume VI: An Ecological Assessment for Anthropogenic Mercury Emissions in the United States, Office of Air Quality Planning \& Standards and Office of Research and Development. 